Cell Research (1999), 9, 51-59

\title{
mad-overexpression down regulates the malignant growth and p53 mediated apoptosis in human hepa- tocellular carcinoma BEL-7404 cells
}

\author{
ZHAO Hua, Yong Hua XU* \\ Shanghai Institute of Cell Biology, Chinese Academy of Sciences, \\ 320 Yueyang Road, Shanghai 200031, China
}

\begin{abstract}
Mad protein has been shown as an antagonist of c-Mycprotein in some cell lines. The effect of Mad protein to the malignant phenotype of human hepatoma BEL-7404 cell line was investigated experimentally. An eukarryotic vector pCDNA III containing full ORF fragment of mad cDNA was transfected into targeted cells. Under G418 selection, stable Mad-overexpressed cells were cloned. Studies on the effect of Mad over-expression in cell proliferation and cell cycle revealed that cell morphology of the Mad-overexpressed BEL-7404-M cells was significantlydifferent from the parent and control vector transfected cells. DNA synthesis, cell proliferation and anchorageindependent growth in soft-agar of the mad-transfected cells were partially inhibited in comparison to control cells. Flow Cytometry analysis indicated that mad over-expression might block more transfectant cells at $\mathrm{G}_{0} / \mathrm{G}_{1}$ phase, resulting in the retardation of cell proliferation. RT-PCR detected a marked inhibition of the expression of cdc25A, an important regulator gene of $G_{0} / G_{1}$ to $S$ phase in cell cycle. It was also found that $\mathrm{Mad}$ protein overexpression could greatly suppress p53-mediated apoptosis in BEL-7404-M $\mathrm{M}_{1}$ cells in the absence of serume. Thus, Mad proteins may function as a negative regulator antagonizing c-Myc activity in the control of cell growth and apoptosis in human hepatocellular carcinoma BEL-7404. cells
\end{abstract}


mad-overexpression and regulation of cell growth and apoptosis

Key words: Mad, c-Myc, cell growth, apoptosis, human hepatoma cells.

\section{INTRODUCTION}

In mammalian cells, c-myc is an important regulator in cell proliferation and links extracellular signals to cell cycle machinery[1]. c-myc also induces cells to undergo apoptosis under some conditions[2]. The effects of c-myc in cell proliferation, differentiation and apoptosis is obviously associated with nuclear regulation network composed of Myc-Max-Mad transcription factors[2],[3]. Max, the stable master protein of the network, regulates the function of network by self-ligation forming a homodimer Max/Max or binding with either Myc or Mad forming the heterodimers Max/Myc or $\operatorname{Max} / \operatorname{Mad}[4]$. For the function of c-myc, it is essential to bind its Myc with Max forming Myc/Max heterodimer. Mad protein belongs to Myc-related family member and regulates the function of c-myc through competitive binding with Max to form the heterodimer Mad/Max[5-7].

It has been found that c-myc is overexpressed in a variety of human cancers. c-myc overexpression is also a positive marker for human hepatocellular carcinoma[8]. In order to investigate the effect of Mad on c-myc mediated malignant growth behavior in human hepatocellular carcinoma cells in which c-myc was overexpressed, human hepatocellular carcinoma BEL-7404 cells were transfected with recombinant madexpressing vector to explore the regulatory role of the overexpressed Mad protein in these cells. The results suggested that Mad overexpression resulted in a significant suppression of malignant growth and transformed phenotype of BEL-7404 cells. In addition, overexpressed Mad protein may also inhibit the p53-mediated apoptosis which can be induced by serum starvation in BEL-7404 cells.

\section{MATERIALS AND METHODS}

\section{Cell culture}

The human hepatocellular carcinoma cell line BEL-7404 cells were maintained in $25 \mathrm{~cm}^{2}$ culture flasks at $37^{\circ} \mathrm{C}$ in a humidified atmosphere of $5 \% \mathrm{CO}_{2}$ in $\mathrm{DMEM}$ medium supplemented with $10 \%$ newborn bovine serum.

\section{Construction of mad expression vector and transfection}

$1.1 \mathrm{~Kb}$ mad cDNA was cleaved and recovered from pVZ1-mad plasmid and ligated into pCDNAIII vector to prepare the mad expressing vector pCDNAlll-mad. BEL-7404 cells were transfected with $20 \mu \mathrm{g}$ pCDNAlll-mad plasmid DNA using calcium phosphate precipitation method and followed by G418 selection for $48 \mathrm{~h}$. Stable transfectants were harvested and cloned. For transient transfection of p53, $20 \mu \mathrm{g}$ pCDNAIII-p53 was used and the transient transfectants were recovered after $48 \mathrm{~h}$.

\section{Northern blot analysis}

Cellular RNA was extracted by the method of Chomczynski and Sacchi. Northern blot analysis 
was performed according to standard procedures using $1.0 \mathrm{~Kb}$ EcoRI fragment of the mad cDNA as a probe.

\section{Anchorage-independent growth assay in soft agar}

The soft agar colony formation assay was used as a measure of the tumorigenicity of madtransfected cells in vitro. After layering $1.2 \%$ agar on a well of 6 -well plate, 5000 cells were resuspended in $0.7 \%$ agar dissolved in tissue culture medium. Colony formation was assessed after an additional $21 \mathrm{~d}$ incubation at $37^{\circ} \mathrm{C}$ with $5 \% \mathrm{CO}_{2}$.

\section{Cell growth curve}

Cell growth curves were plotted as cell number versus time. $1 \times 10^{5}$ cells were plated in every flask and incubated in DMEM either with or without $10 \%$ serum at $37^{\circ} \mathrm{C}, 5 \% \mathrm{CO}_{2}$. Cell counting were performed continuously for $5 \mathrm{~d}$.

\section{Growth inhibition assays}

Cells were plated in 96 -well tissue culture plates at density of $1 \times 10^{4}$ cells/well. Grown overnight and then placed in $200 \mu \mathrm{l}$ fresh tissue culture medium with or without $10 \%$ serum, $1 \mu \mathrm{Ci}^{3} \mathrm{H}$ thymidine was added to every well. After $10 \mathrm{~h}$ culture, cells were washed and lysed, the amount of $3 \mathrm{H}$ thymidine incorporated into DNA was quantitated using a scintillation counter.

\section{Reverse transcription-PCR of cdc25A}

$2 \mu \mathrm{g}$ total RNA extracted from cells was reversely transcribed using $200 \mathrm{ng}$ reverse primers, 30 units of MMLV reverse transcriptase, 20 units RNasin and $2.5 \mathrm{mM}$ dNTP in a volume of $20 \mu \mathrm{l}$ for $1 \mathrm{~h}$ at $37^{\circ} \mathrm{C}$ water bath. Then, $2 \mu \mathrm{l}$ reverse transcription products were used for following PCR. In a total of $25 \mu \mathrm{l}$ reaction mixture, $10 \mathrm{pmol} 3$ ' primer and $10 \mathrm{pmol} 5$ ' primer, $1 \times$ Taq buffer and 1 unit Taq polymerase were mixed. The reaction run for 30 cycles, each consisted of $94^{\circ} \mathrm{C}$ denaturation for $30 \mathrm{sec}, 55^{\circ} \mathrm{C}$ annealing for $60 \mathrm{sec}, 72^{\circ} \mathrm{C}$ extension for $60 \mathrm{sec}$ and with final extension at $72^{\circ} \mathrm{C}$ for $10 \mathrm{~min}$. The forward 5' primer of cdc25A is: 5' GAGGAGTCTCCACCTG GAAGAC 3' and the reverse 3' primer of cde25A is: 5' GCCATTCAAAACAGA GCCATAA 3 ' As internal standard,PCR of $\beta$-actin was performed using 5' primer 5, A C A C T G T G C C C A T C T A C G A G G G G 3 , a n d 3 , p r i m e r 5 , ATGATGGAGTtGAAGGTAGTTTCGTGGAT 3’.

\section{Flow cytometry analysis}

Cells from subconfluent culture were resuspended, washed with PBS and fixed in sodium citrateat $4^{\circ} \mathrm{C}$ for $30 \mathrm{~min} .5 \mathrm{ml}$ propidium iodide $(50 \mu \mathrm{g} / \mathrm{ml})$ was added to $10^{6}$ cells for 20 min at 4 ${ }^{\circ} \mathrm{C}$ without light. The total DNA content per cell was assessed by analysis of florescence using a FACS can flow cytometer.

\section{RESULTS}

pCDNAIII-mad expression vector transfection and the morphology of madoverexpressed transfectants

Recombinant expressing plasmid pCDNAlll-mad containing a $1.1 \mathrm{~kb}$ full length mad ORF cDNA was transfected into human hepatocellular carcinoma BEL-7404 cells using calcium phosphate precipitate method. Vector pCDNAlll without mad insert was used as control plasmid for transfection. Through G418 selection, most parent BEL-7404 cells died in 2-3 w culture followed by the formation of many G418 resistant cell foci. Two 
mad-overexpression and regulation of cell growth and apoptosis

mad-expressing vector transfected clones, BEL-7404- $\mathrm{M}_{1}$ and BEL-7404- $\mathrm{M}_{2}$, and one empty vector transfected clone BEL-7404- $\mathrm{M}_{0}$ were picked up randomly and transfer to new culture plate in fresh medium. Northern blot hybridization shown in Fig 1 indicated the over-expression of $1.1 \mathrm{~Kb}$ mad mRNA in both mad-expressing vector transfected BEL7404-M (Fig 1, A-1) and BEL-7404-M $_{2}$ (Fig 1, A-2) cells in comparison with parent cells

Fig 1. Northern blot hybridization of madexpressed transfectants

A. mad cDNA was used as probe to detect the expression of mad in BEL7404-M1 cells(1), BEL-7404- M2 cells (2) and parent BEL-7404 cells(3)

B. $\beta$-actin probe hybridization was used as internal control in different cell samples.

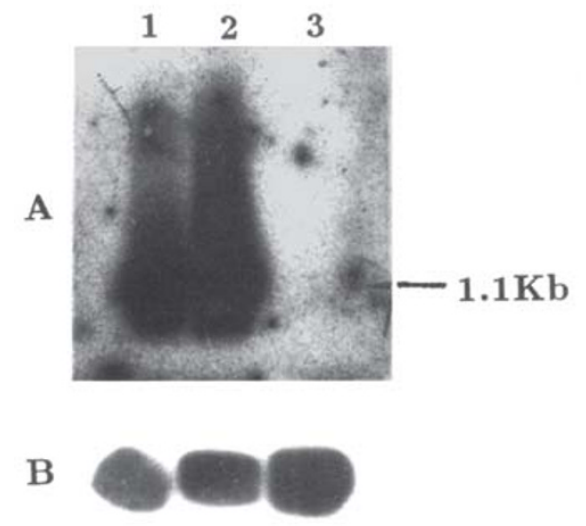

BEL-7404 (Fig 1, A-3) and control BEL-7404-M 0 cells (data not shown).

Morphology comparison between mad-overexpressed BEL-7404-M $\mathrm{M}_{1}$ cells, control BEL7404- $\mathrm{M}_{0}$ cells and parent cells as shown in Fig 2 indicated an obvious changes of cell shape, cell density, cell adhesion in mad-overexpressed cells. It is hard to detect any difference between parent cells and control BEL-7404- $\mathrm{M}_{0}$ cells. The results suggested the morphological changes in mad-overexpressed cells (Fig 2, C) were logically associated with the activ-

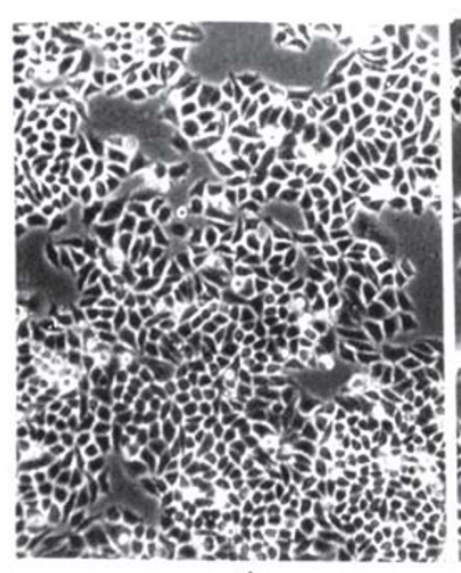

A

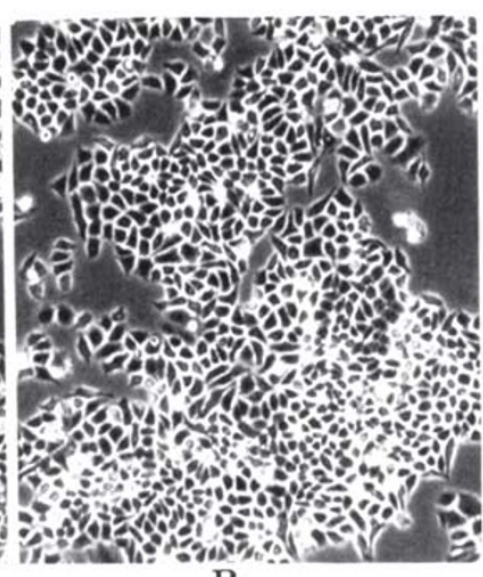

B

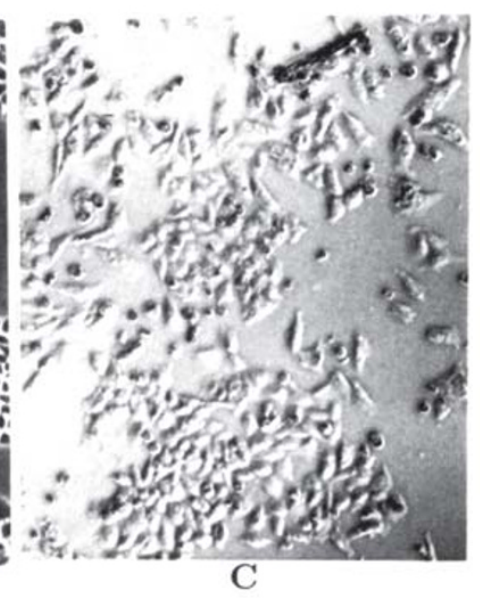

Fig 2. Morphology comparison of parent cells (A), control BEL-7404-M $\mathrm{M}_{0}$ cells (B) and madoverexpressed BEL-7404-M $\mathrm{M}_{1}$ cells (C). 
ity and function of Mad proteins.

Effect of Mad expression on DNA synthesis, cell proliferation and anchorageindependent growth in soft agar of human hepatoma cells

Mad overexpression significantly inhibited the DNA synthesis of BEL-7404-M 1 cells as shown in Fig 3. ${ }^{3} \mathrm{H}$ thymidine incorporation in BEL-7404- $\mathrm{M}_{1}$ cells were reduced in comparison with parent cells and control BEL-7404- $\mathrm{M}_{0}$ cells, no matter in culture with serum or without serum. Althogh, there were some effects of serum starvation on the ${ }^{3} \mathrm{H}$-thymidine incorporation in BEL-7404 cells and BEL-7404- $\mathrm{M}_{0}$ cells, but, BEL-7404-

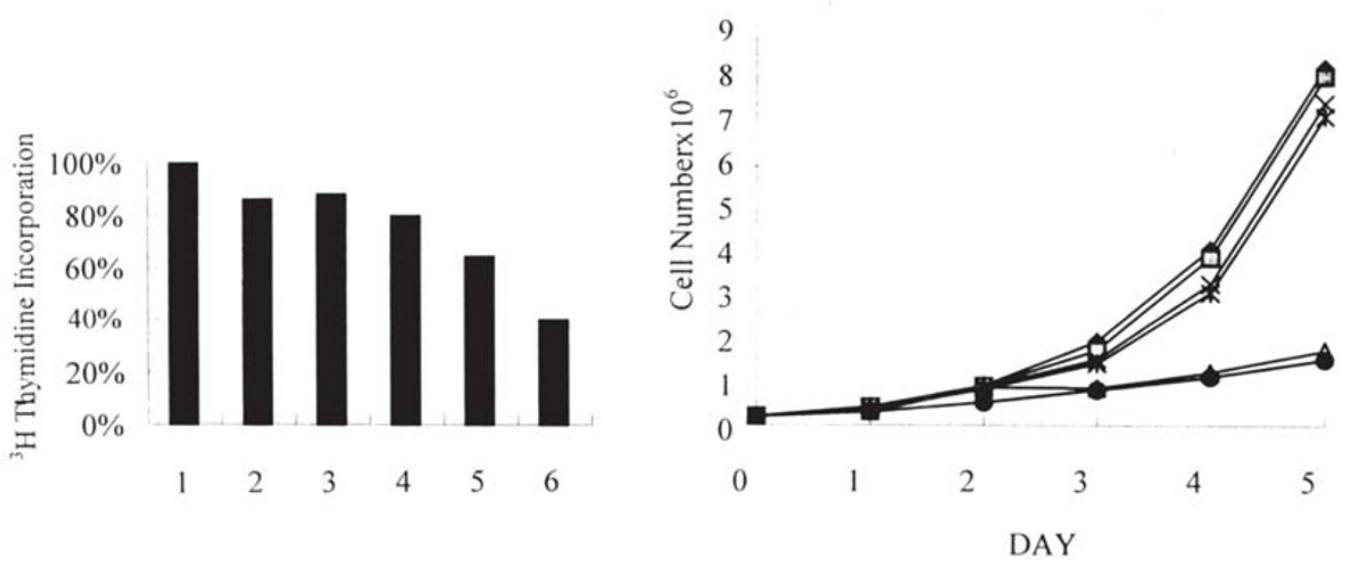

Fig 3. ${ }^{3} \mathrm{H}$-Thymidine incorporation in BEL7404- $\mathrm{M}_{1}$ BEL-7404- $\mathrm{M}_{0}$ and BEL7404

Fig 4. Effect of Mad expression on cell proliferation in control and mad-cDNA transfected human hepatoma cells. BEL-7404 cells in culture with or without serum. cells in culture with serum(- - - ) or without $\operatorname{serum}(-\times-)$ BEL-7404-M 0 cells in culture with serum ( $\square-$-) or without serum (一*-) BEL-7404-M $\mathrm{M}_{1}$ cells in culture with $\operatorname{serum}(-\mathbf{\Delta}-)$ or without $\operatorname{serum}(-\bullet-)$

$\mathrm{M}_{1}$ cells (Fig 3, compare 5 and 6) appeared to be more sensitive to serum starvation.

The results of cell counting shown in Fig 4 confirmed the inhibition activities of Madoverexpression on the growth of BEL-7404-M $\mathrm{M}_{1}$ cells. During five d culture, parent cells and control BEL-7404-M $\mathrm{M}_{0}$ cells showed rapidly growing potentialities no matter in serumcontaining or serum free medium, with cell number reaching seven to eight fold of that of original culture on fifth day. A serious blocking of cell proliferation for BEL-7404-M cells was happened on third to fifth day and there was no marked improvement to cell growth even in the presence of serum in these mad-overexpressed hepatoma cells. 
mad-overexpression and regulation of cell growth and apoptosis

Anchorage-independent growth in soft agar is one of the characteristics for malignant cells and transformed cells in vitro compared with normal cells. Anchorage-independent growth assay found that the ability of colony formation of mad-over-expressed BEL7404- $\mathrm{M}_{1}$ cells was dramatically reduced as shown in Tab 1 . There was no obvious difference in growth ability in soft agar between the empty vector transfected BEL-7404-M $\mathrm{M}_{0}$ cells and the parent cells.

Tab 1. The inhibitory effect of Mad-overexpression on the colony formation of cells in soft agar of BEL-7404-M 1 cells

\begin{tabular}{cc}
\hline Cells & Number of colonies in soft agar \\
\hline BEL-7404 Cell & 1104 \\
BEL-7404-M $\mathrm{M}_{0}$ cell & 1031 \\
BEL-7404-M $\mathrm{M}_{1}$ cell & 151 \\
\hline
\end{tabular}

The possible mechanism of Mad overexpression in relation to cell growth inhibition

Flow cytometry analysis as shown in Tab 2 demonstrated that in the population of mad-overexpressed BEL-7404-M $\mathrm{M}_{1}$ cells, the proportion of cells in the $\mathrm{G}_{0} / \mathrm{G}_{1}$ phase increased, and concurrently, the proportion of cells in the Sphase and $\mathrm{G}_{2} / \mathrm{M}$ phase decreased. It indicated that a higher percentage of mad-overexpressed BEL-7404-M $\mathrm{M}_{1}$ cells were blocked in $G_{0} / G_{1}$ phase of cell cycle than parent cells and control BEL-7404-M $M_{0}$ cells, resulting in the inhibition of proliferation of BEL-7404-M cells.

Tab 2. Cell cycle analysis of mad-overexpressed

\begin{tabular}{|c|c|c|c|}
\hline \multirow[t]{2}{*}{ Cells } & \multicolumn{3}{|c|}{ Percentage in cell cycle } \\
\hline & $\mathrm{G}_{0} / \mathrm{G}_{1}$ & $\mathrm{~S}$ & $\mathrm{G}_{2} / \mathrm{M}$ \\
\hline BEL-7404 cells & $48.50 \%$ & $26.95 \%$ & $24.45 \%$ \\
\hline BEL-7404-M ${ }_{1}$ cells & $63.37 \%$ & $18.40 \%$ & $18.23 \%$ \\
\hline BEL-7404-Mo cells & $50.15 \%$ & $24.45 \%$ & $25.40 \%$ \\
\hline
\end{tabular}

Since cdc25A is an important gene in the regulation of cell cycle, controlling the entry from G1 phase to S phase, RT-PCR method was used to detect RNA expression of cdc25A in BEL-7404-M $\mathrm{M}_{1}$, BEL-7404-M $\mathrm{M}_{0}$ and parent cells. The results demonstrated that mad overexpression greatly inhibited cdc25A RNA expression in BEL-7404-M 1 cells (Fig 5, A1), but there was no obvious difference in cdc25A RNA expression between BEL-7404-M cells and parent cells (Fig 5, A-2 and 3). $\beta$-actin RT-PCR in Fig 5 B was used as internal control.

The effect of Mad expression on p53 mediated apoptosis of BEL-7404 cells

Tab 3 indicated that there was no significant difference in spontaneous apoptosis among parent cells, control BEL-7404-M $\mathrm{M}_{0}$ cells and mad-overexpressed BEL-7404-M 1 cells cultured in either serum-containing or serum-free medium. However, after being tran- 
siently transfected with p53 gene expression vector, the apoptosis was significantly stimulated by serum starvation from 5.37\% to 34.69\% in BEL-7404 cells and from 5.85\% to $31.56 \%$ in control BEL-7404- $\mathrm{M}_{0}$ cells. Interestingly, the serum starvation inducible apoptosis was mostly blocked in p53 transiently transfected BEL-7404-M $\mathrm{M}_{1}$ cells, suggesting an effect of Mad proteins on the control of apoptosis in these mad-overexpressed hepatocellular carcinoma cells.

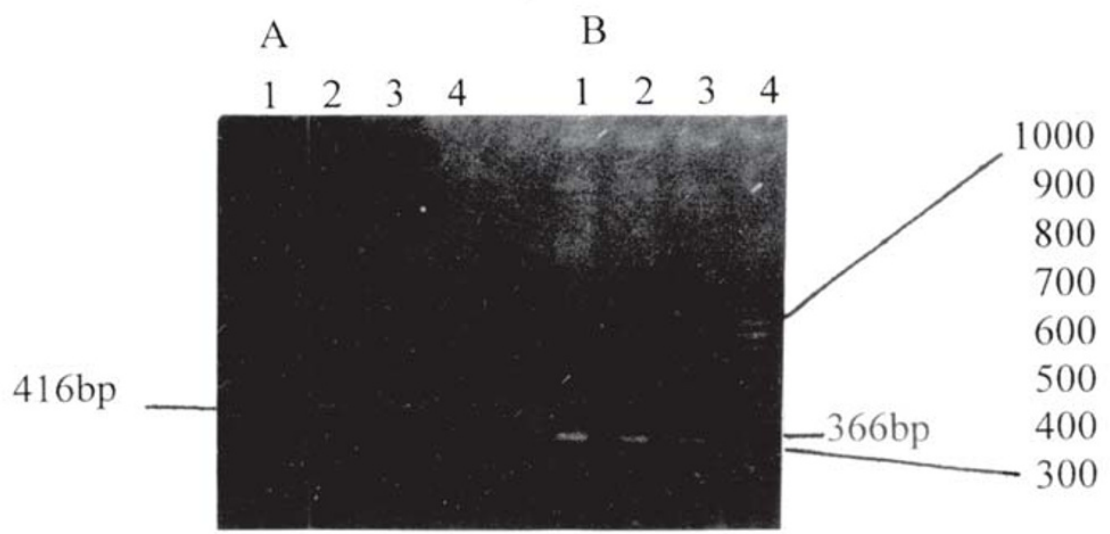

Fig 5. RT-PCR of cdc25A gene expression in BEL-7404-M $\mathrm{M}_{1}$ cells and their control cells
A. cdc25A RNA expression
B. $\beta$-actin RNA expression
BEL-7404-M 1 cells;
3. BEL-7404 cell;
BEL-7404-M cells;
4. $100 \mathrm{bp}$ ladder marker.

Tab 3. Serum starvation inducible apoptosis in p53 transfected BEL-7404 cells, BEL-7404-Molls and BEL-7404-M $\mathrm{M}_{1}$ cells

\begin{tabular}{|c|c|c|}
\hline \multirow[t]{2}{*}{ Cells } & \multicolumn{2}{|c|}{$\%$ of apoptotic cells } \\
\hline & with serum & without serum \\
\hline BEL-7404 cell & $1.75 \%$ & $4.47 \%$ \\
\hline p53 transfected BEL-7404 cells & $5.37 \%$ & $34.69 \%$ \\
\hline BEL-7404-M cells & $3.16 \%$ & $5.37 \%$ \\
\hline p53 transfected BEL-7404-Mo cells & $5.85 \%$ & $31.56 \%$ \\
\hline BEL-7404-M cells & $4.87 \%$ & $5.44 \%$ \\
\hline p53 transfected BEL-7404-M $\mathrm{M}_{1}$ cells & $7.55 \%$ & $10.76 \%$ \\
\hline
\end{tabular}

\section{DISSCUSION}

Numerous studies suggest that c-Myc is intimately involved in th e regulation of cell proliferation[1, 2]. Interestingly, several reports have demonstrated a reciprocal expression of c-Myc and Mad in the cells[3-6]. It is well established that Mad acts as a competitor of Myc in binding with Max to regulate the activity of Myc in the cells. Mad family members involved Mad and Mxi1. The expression of mxi1 and mad have both been correlated with the differentiation of hematopoietic cells, keratinocytes, instestinal 
mad-overexpression and regulation of cell growth and apoptosis

cells, and neural cells[4, 7]. In the present report, it was demonstrated that reintroduction of mad into human hepatocellular carcinoma BEL-7404 cells resulted in growth retardation and reduced tumorigenecity in vitro as well. The down-regulation function of the mad was definitely associated with c-myc. In mad-overexpressed BEL7404-M $\mathrm{M}_{1}$ cells, the expression of cdc25A, an important c-myc target gene which controlls cell progressing from $\mathrm{G}_{1}$ phase to $\mathrm{S}$ phase in cell cycle[9], was obviously inhibited. The results indicated the negative action of Mad is opposite to c-Myc oncoprotein. We have not analyzed the genetics of mad gene in BEL-7404 cells, but, Northern blot hybridization showed undetectable level of mad mRNA expression in the cells. Frequent LOH of the mad family members locus has been found in some human cancers suggesting that mad family members may be candidate tumor suppressor genes[10]. The tumor suppressor action of mad gene was also supported by the findings that the members of Mad family were able to counteract the effects of c-Myc in several tumor cell systems. For example, the action of adenoviral mad expressing vector in U373MG glioblastroma cells [11] and the regulatory function of overexpressed Mxi1 in inducible Mxi1 expression system transfected human glioblastoma cells leading to increased accumulation of cells in $\mathrm{G}_{2}-\mathrm{M}[10]$.

It has been known that c-myc can induce the apoptosis of the cells cultured in low serum or serum-free medium[12]. The mitogens such as the growth factors IGF, PDGF, EGF in culture medium effectively blocked the apoptosis induced by c-myc[13]. p53 is another key regulator in the control of apoptosis. In the present study, we have demonstrated a possible mechanism regulating apoptosis in human hepatoma cell. Human hepatocellular carcinoma BEL-7404 cells, a c-myc over-expressed cells, did not happen to trigger, per se, apoptosis when the serum was withdrawn from the medium. However, if these hepatoma cells were transiently transfected with wild type of p53 gene, they became serum starvation sensitive in apoptosis induction. p53 is a suppressor gene. The mutation of p53 gene was found to be occurred in many kinds of human cancer cells, including hepatoma cells. We have detected the mutation of p53 in BEL-7404 hepatocellular carcinoma cells (unpublished data). The results in this paper suggested that mutant p53 gene in BEL-7404 cells prevented the occurrence of apoptosis caused by serum starvation. Transient re-introduction of wild p53 gene into BEL-7404 cells made the cells responsive to serum starvation in inducing apoptosis. The regulatory function of p53 in apoptosis had been reported in other cell lines as leukemia cells indicating that the overexpression of wild type p53 gene caused apoptosis of these cells, on the other hand, mutant p53 gene was able to prevent apoptosis[14]. Interestingly, we found the activity of wild type p53 gene in mediating apoptosis was silent in madoverexpressed BEL-7404-M $\mathrm{M}_{1}$ cells. It is reasonable to suggest that p53 and cmyc may be interconnected in their regulation of cell apoptosis and Mad protein competes with cMyc in binding with Max to interfere the function of c-Myc in the regulation of both cell growth and apoptosis.

Mad functions as an antagonist of c-Myc in cell life regulating the growth, 
differentiation and apoptosis of the cells. It may also play an amazing role in tumorigenesis and malignant behavior in cancer cells. The molecular mechanism of Mad function in Myc-Max-Mad network and signal pathway needs further investigation.

\section{ACKNOWLEGEMENTS}

This work was supported by Chinese National Natural Science Fundation (No: 39670802).

\section{REFERENCES}

[1] Dang CV, Lee LA. c-Myc function in neoplasia. Austin. TX: R.G. Landes Company. 1995:196.

[2] Henriksson M, Luscher B. Proteins of the Myc network essential regulators of cell growth and differentiation. Adv Cancer Res 1996; 68:109-82.

[3] Amati B, Land H. Myc-Max-Mad: a transcription factor network controlling cell cycle progression, differentiation and death. Curr Opin Genet Dev 1994; 4:102-8.

[4] Amati B, Brooks MW, Levy N, Littlewood TD, Evan GI, Land H. Oncogenic activity of the c-Myc protein requires dmerization with Max. Cell 1993; 72:233-45.

[5] Amati B, Littlewood TD, Evan GI, Land H, EMBOJ. the c-Myc protein induces cell cycle progression and apoptosis through dimerization with Max. 1993; 12:5083-7.

[6] Ayer DE, Eisenman RN. A switch from Myc: Max to heterocomplexes accompanies mono-cyte/ macrophage differentiation. Genes and Dev 1993; 7:2110-9.

[7] Zervos AS, Gyuris J, Brent R. Mxi1, a protein that specially interacts with Max to bind Myc-Max recognition sites. Cell 1993; 72:223-32.

[8] Levine AJ. The tumor suppressor genes. Annu Rev Biochem 1993; 62:623-51.

[9] Galaktiorov K, Chen XC, Beach D. cdc25 cell cycle phosphatase as a target of c-myc. Nature 1996; 382:511-7.

[10] Wechsler DS, Shelly CA, Petroff CA, Dang CV. mxi1, a putative tumor suppressor gene, suppressed growth of human glioblastoma cells. Cancer Research 1997; 57:4905-12.

[11] Chen J, Willingham T, Margraf LR, Schreiber AN, DePinho RA, Nisen PD. Effects of the myc oncogene antagnist, mad, on proliferation cell cycling and the malignant phenotype of the human brain tumor cells. Nat Med 1995; 1:638-43.

[12] Evan GI, Wyllie AH, Gilbert CS, Littlewood TD, Lard H, Brooks M, Waters CM, Penn LZ, Hancock DC. Induction of apoptosis in fibroblasts by c-Myc protein. Cell 1992; 69:119-28.

[13] Harrington EA, Bennett MR, Fanidi A, Evan GI. c-Myc-induced apoptosis in fibroblasts is inhibited by specific cytokines, EMBOJ 1994; 13:3286-95.

[14] Yonish-Rouach E, Resnitrky RD, Lotem J, Sachs L, Kimchi A, Oren M. wide-type p53 induces apoptosis of myeloid leukemic cells that is inhibited by interleukin-6. Nature 1991; 352:345-7. 